\title{
Interactive comment on "The Warming Tibetan Plateau improves winter air quality in the Sichuan Basin, China" by Shuyu Zhao et al.
}

\section{Anonymous Referee \#1}

Received and published: 5 May 2020

\section{General comments:}

In this manuscript, the authors focus on the effect of warming Tibetan Plateau on air quality in the Sichuan Basin, China. Specifically, they address the $2{ }^{\circ} \mathrm{C}$ warming causes an increase in the PBL height and a decrease in the relative humidity in the basin. The elevated PBL height strengthens vertical diffusion of PM2.5, while the decreased $\mathrm{RH}$ significantly reduces secondary aerosol formation. The authors highlight that the recent warming plateau has improved air quality in the basin. The results of this work are based on the WRF-Chem simulations and extensive observation. The analysis is mostly sound, the manuscript is well written, but some details need clarify. I recommend a minor revision with my comments listed below.

Specific comments: 1. In line151, please further explain what does 'top-down' 
method" means here and how to use the 'top-down' method to constrain the emission inventory via comparing the simulations with the measurements?

2. In line 164-165, in the configuration of the sensitivity simulation, how to set the temperature increment to $2 \mathrm{~K}$ ? Is it just increase the temperature in all levels and all grids of the model above Tibetan Plateau (TP)? Does the $2 \mathrm{~K}$ increment set at the beginning of model simulation or need nudging in every step of the simulation? Are the temperature increment same in verticals or just at the surface?

3. In line 231-232, is it correct here "the overestimated PM2.5 concentration is mainly caused by the overestimated wind speed"? Or underestimated wind speed?

4. Could you further explain the thermodynamic reasons of the winds and PBLH changes due to $2 \mathrm{~K}$ warming over TP in figure 7 and the description in line 263269 "easterly winds over the basin enhance while westerly wind over the plateau weaken......northerly winds over the basin slightly enhance,"?

5. In line 293-295, similarly, could you further explain the mechanism of "a maximal temperature reduction located at $1.5 \mathrm{~km}$ to $3 \mathrm{~km}$ above the ground (Figure 9a)"?

6. Related to comments 4 and 5, the paragraph from line 302-311 did not make very clear discussion on the changes of wind and temperature gradient. I suggest the comparison of the changes of pressure-difference between TP and basin, and see the circulation changes could easily explain the issues in comments 4 and 5 .

7. I don't think the ascending motion in this study is similar to the plateau "heat pump" effect raised by Lau (2016).

Technical corrections:

1. I am misleading by the figure 6 in the first look and regards they are pie charts in percentage of species. Plot them as columns could be better.

2. Setting figure 11 as figure $10 \mathrm{c}$ is reasonable. 
Interactive comment on Atmos. Chem. Phys. Discuss., https://doi.org/10.5194/acp-2020-196, 2020.
ACPD

Interactive comment 